\title{
An Acquired Antithrombin Autoantibody Directed toward the Catalytic Center of the Enzyme
}

\author{
Pierre Sié," Annie Bezeaud," Dominique Dupouy," Gisèle Archipoff," Jean-Marie Freyssinet," Jean-Michel Dugoujon," \\ Guy Serre,' Marie-Claude Guillin, ${ }^{\ddagger}$ and Bernard Boneu* \\ ${ }^{*}$ Laboratoire Hemostase, Centre Régional de Transfusion Sanguine, Centre Hospitalier Universitaire Purpan, Toulouse; ${ }^{\ddagger}$ Laboratoire de \\ Recherche sur l'Hémostase et la Thrombose, Fac. Xavier Bichat, Université Paris VII; Institut National de la Santé et de la Recherche \\ Médicale U 311, Centre Régional de Transfusion Sanguine, Strasbourg; "Centre de Recherche sur le Polymorphisme \\ Génétique-Centre National de la Recherche Scientifique; and'Laboratoire de Biologie Cellulaire, \\ Centre Hospitalier Universitaire Purpan, Toulouse, France
}

\begin{abstract}
Antibody inhibitors against human thrombin are rare and have remained poorly characterized. We report the case of a $40-y r-$ old patient who developed a potent thrombin inhibitor revealed by mild bleeding symptoms and marked prolongation of most laboratory clotting times. After two years of evolution, he died from cerebral hemorrhage. The inhibitor, a polyclonal IgG, was associated with hematological and immunological criteria of autoimmune disorder. Antithrombin IgG was isolated from the patient's plasma by protein A- and thrombin-affinity chromatography. Fab fragments inhibited amidolytic activity of $\alpha$ thrombin, and thrombin-thrombomodulin catalyzed protein $\mathbf{C}$ activation with a $K_{\mathrm{i}}$ of $\sim 10^{-8} \mathrm{M}$ in a noncompetitive manner. Alpha to gamma conversion of thrombin resulted in a moderate loss of affinity for the inhibitor. Upon complex formation of thrombin with staphylocoagulase or $\alpha 2$-macroglobulin ( $\alpha 2 \mathrm{M})$, inhibition was decreased by two orders of magnitude and acquired an apparent competitive character. In Western blot experiments, the antibody reacted with active alpha-thrombin, did not react with chloromethylketone-inhibited thrombin and reacted with a lower affinity with iPr2P-thrombin. The inhibitor did not block thrombin binding to benzamidine-, heparin-, or fibrin-Sepharose, but displaced proflavin from its complex with thrombin. Taken together, these results indicate that the patient's autoantibody recognized a conformational structure which includes, at least in part, the apolar binding site adjacent to the catalytic site of thrombin. (J. Clin. Invest. 1991. 88:290296.) Key words: antithrombin • anticoagulant • serine protease - autoimmunity $\bullet$ hirudin $\bullet$ hemorrhage
\end{abstract}

\section{Introduction}

Nonneutralizing antiprothrombin antibodies are the most common inhibitors, associated with the lupus anticoagulant in patients with systemic lupus erythematosus and various diseases (1). In contrast, neutralizing thrombin antibodies rarely occur. In addition to the antibodies induced by the exposure to bovine topical thrombin during surgical procedure (see reference 2 for a review), isolated cases of antithrombin autoantibodies have been reported in patients with systemic lupus erythematosus (3), liver cirrhosis (4), duodenal ulcer treated with ci-

Address reprint requests to Dr. P. Sie, Lab. Hémostase, CRTS, CHU Purpan, 31052, Toulouse Cedex, France.

Received for publication 22 October 1990 and in revised form 15 February 1991.

J. Clin. Invest.

(c) The American Society for Clinical Investigation, Inc.

0021-9738/91/07/0290/07 \$2.00

Volume 88, July 1991, 290-296 metidine and antiacids (5), or without apparent disease (6). In some instances, these inhibitors have been associated with bleeding symptoms. The specificity of these antibodies has never been extensively investigated.

We report the case of a patient who developed a very potent human thrombin inhibitor in the apparent absence of underlying disease. He experienced mild bleeding symptoms for two years and eventually died from cerebral hemorrhage. The inhibitor, a polyclonal IgG, was purified and characterized. It recognized antigenic determinants closely associated with the catalytic site of the enzyme.

The present observation is the first example of an autoantibody directed towards the catalytic center of a plasma serineprotease. Although the mechanism of selective production of such an inhibitor is unknown, its pathogenic consequence, i.e., the inhibition of the full spectrum of enzymatic activities of thrombin, is clearly evidenced.

\section{Methods}

\section{Case Report}

The patient was a 40-yr-old man who began to bleed in April 1986 (subcutaneous hematoma, gum bleeding, and microhematuria). At this stage, plasma was unclottable by any routine clotting assay (prothrombin time [PT], ${ }^{1}$ activated partial thromboplastin time [APTT], and thrombin time [TT]). Platelet count was $135,000 / \mu l$. There was a slight hypergammaglobulinemia (IgG, $18 \mathrm{~g} /$ /iter) without monoclonal abnormality. Investigation for malignancy remained negative. Bone marrow examination demonstrated an increased number of megakaryocytes, with no evidence of myeloma or lymphoma. The Coombs' test revealed the presence of anticomplement antibodies. The search for antiDNA and antinuclear antibodies was negative. As the hemorrhagic symptoms were minor and as there was no clinical evidence of autoimmune disease, the patient was not treated.

The patient was referred to us two years later, in April 1988. At this stage, the physical examination was normal, except for the presence of large subcutaneous hematoma. There was no clinical evidence of systemic lupus erythematosus (7), but the following were suggestive of an autoimmune disease: $(a)$ false positive serologic tests for syphilis with a negative test of Treponema pallidum immobilization; $(b)$ antinuclear antibodies at titer $1 / 32$ by immunofluorescence assay; $(c)$ anti-doublestrand DNA were at $11 \%$ (Farr's test); however, the search for antiDNA by immunofluorescence on Crithidia luciliae was negative; $(d)$ platelet count was $65,000 / \mu 1$ and antiplatelet antibodies were detected by indirect immunofluorescence; $(e)$ antiphospholipid antibodies evaluated by two ELISA procedures (Asserachrom APA, Diagnostica Stago, Asnieres, France, and Malakit cardiolipin, Biolab, Limal, Belgium) were strongly positive. There was no biological evidence of myeloma or

1. Abbreviations used in this paper: APTT, activated partial thromboplastin time; ${ }_{\mathrm{PPr}} \mathrm{P}-\mathrm{F}$, diisopropylfluorophosphate; $\alpha 2 \mathrm{M}, \alpha 2$-macroglobulin; PPACK, D-phenylalanyl-L-prolyl-L-arginine chloromethyl ketone; PT, prothrombin time; TLCK, $N$ - $\alpha$-tosyl-L-lysine chloromethyl ketone; TT, thrombin time. 
lymphoma. Immunoglobulin levels and serum immunoelectrophoresis were normal. IgG electrofocalization did not reveal any monoclona or oligoclonal production. Serologic tests for hepatitis B and human immunodeficiency virus were negative.

The results of the investigation of hemostasis at this time are shown in Table I. Simplate bleeding time was not performed for fear of excessive bleeding. By using the puncture method of Ivy, bleeding time was 9 min (normal value, $<5 \mathrm{~min}$ ), i.e., moderately prolonged, in relation with thrombocytopenia. Thrombin time was out of limits but snake venom times were normal, suggesting the presence of a thrombin inhibitor. The antithrombin activity was quantitated by measuring the TT of serial dilutions of patient's plasma in normal plasma. It was found to be equivalent to $3 \mathrm{IU} / \mathrm{ml}$ of unfractionated heparin or $24 \mu \mathrm{g} / \mathrm{ml}$ of recombinant hirudin (r-Hv2-Lys 47, 15,858 ATU/mg, a gift from Mr. G. Defreyn, Sanofi-Recherche, Toulouse) in normal human plasma. There was no anti-factor Xa activity measurable by amidolytic assay (Stachrom heparin, Diagnostica Stago). Addition of patient's plasma (or purified Fab solution, see below) to normal platelet-rich plasma completely inhibited thrombin-induced platelet aggregation but did not change the response to collagen or ADP.

The clotting factor levels were normal except for prothrombin. Low levels of prothrombin activity and, to a lesser extent, of prothrombin antigen were associated with the presence of prothrombin-antiprothrombin antibody complexes in the patient's plasma as demonstrated by crossed immunoelectrophoresis (not shown).

The immunological nature of the thrombin inhibitor was confirmed and a treatment with prednisolone and azathioprine was started. $4 \mathrm{~d}$ after, the patient developed a cerebral hemorrhage and died in spite of transfusion with prothrombin concentrates and plasma exchange therapy. An autopsy could not be performed.

\section{Experimental Procedures}

Isolation of the thrombin inhibitor. Just before starting the immunosuppressive therapy, a plasmapheresis was performed and the plasma col-

Table I. Hemostasis Parameters, April 1988

\begin{tabular}{lcc}
\hline & $\begin{array}{c}\text { Reference } \\
\text { values }\end{array}$ & $\begin{array}{c}\text { Patient's } \\
\text { values }\end{array}$ \\
\hline APTT $(s)$ & $32-36$ & $>300$ \\
PT $(s)$ & $10-12$ & $>300$ \\
TT $(s)$ & $18-20$ & $>300$ \\
TT + protamine $(s)$ & $16-20$ & $>300$ \\
Reptilase time $(s)$ & $16-20$ & 18 \\
Ancrod time $(s)$ & $10-16$ & 12 \\
Staphylothrombin time $(s)$ & $18-20$ & 21 \\
Fibrinogen $(g / l i t e r)$ & $2-4$ & 4.5 \\
Prothrombin $(\%)$ & $70-100$ & \\
$\quad$ Clotting assay & & $<5$ \\
Electroimmunoassay & & 40
\end{tabular}

Blood was collected on citrated vacutainers (Becton-Dickinson, reference 606608 ). Clotting times were recorded on a KC 10 automat (AHS-DADE). Assays were performed on citrated plasma by conventional procedures using the following reagents: automated APTT (Organon Teknika, Durham, NC), rabbit brain thromboplastin (BioMerieux, Marcy-l'Etoile, France), reptilase (Diagnostica Stago), ancrod (Boehringer Mannheim) and staphylothrombin (Diagnostica Stago). TT was out of limits, irrespective of the origin of thrombin: equine (Houdé, Puteau, France), bovine (Hoffman-LaRoche Co., Nutley, NJ) or human (Ortho, Diagnostic Systems, Raritan, NJ). Fibrinogen was measured by a clotting assay after 1:20 plasma dilution in buffer (Fibriprest Stago). Levels of factors V, VII, VIII, IX, X, XI, and XII (one-stage assays) and antithrombin III antigen were in the normal range. lected on citrate/citric acid/dextrose (Haemonetics, Braintree, MA) was stored in aliquots at $-70^{\circ} \mathrm{C}$ until use.

During the purification procedure, IgG concentration was measured by radial immunodiffusion (Nor Partigen IgG, CalbiochemBehring Corp., La Jolla, CA). The thrombin inhibitory activity was estimated as the reciprocal of the sample dilution which doubled the TT of a normal plasma in mixing experiments.

As preliminary experiments indicated that the inhibitor was an IgG, we chose to isolate the inhibitor by a combination of protein A- and thrombin-affinity chromatographic steps.

Human thrombin, purchased from the Centre National de Transfusion Sanguine (Paris) was coupled to $\mathrm{CNBr}$-activated Sepharose (Pharmacia Fine Chemicals AB, Uppsala, Sweden) according to the manufacturer's instructions. The material eluted from protein A-Sepharose (Pharmacia Fine Chemicals AB) with $0.1 \mathrm{M} \mathrm{Gly}-\mathrm{HCl}, \mathrm{pH} 2.5$, was dialyzed against PBS $(0.15 \mathrm{M} \mathrm{NaCl}, 0.1 \mathrm{M}$ phosphate buffer, $\mathrm{pH}$ 7.00), and run down a column of $20 \mathrm{ml}$ of thrombin-Sepharose equilibrated with the same buffer. The column was washed with $0.5 \mathrm{M} \mathrm{NaCl}$, $0.1 \mathrm{M}$ phosphate buffer, $\mathrm{pH} 7.00$. The flowthrough fraction and the washes were pooled and dialyzed against PBS, whereas bound material was eluted with $3 \mathrm{M}$ ammonium thiocyanate. Three chromatographic runs were required to completely deplete the antithrombin activity of the IgG isolated from $100 \mathrm{ml}$ of patient's plasma. Finally, the antithrombin IgG was concentrated by precipitation with saturated ammonium sulfate and extensively dialyzed against PBS. In the following, this material will be referred to as "high-affinity IgG" (HA-IgG).

The IgG subclasses were quantitated in plasma, eluates of protein A-Sepharose and eluates of thrombin-Sepharose using an ELISA procedure (Biomakor, Rehovot, Israel). Gm typing was performed by inhibition of hemagglutination (8).

Kinetic analysis of thrombin inhibition. Fab fragments of HA-IgG were prepared by papain digestion to enable kinetic analysis with monovalent species.

Purified human $\alpha$ thrombin (3,000 NIH U/mg), $\beta$ thrombin (60 $\mathrm{NIH} \mathrm{U/mg),} \mathrm{gamma} \mathrm{thrombin} \mathrm{(} 30 \mathrm{NIH} \mathrm{U/mg),} \mathrm{protein} \mathrm{C,} \mathrm{and} \mathrm{throm-}$ bomodulin were prepared and quantitated as previously described (912). The synthetic substrates of thrombin and activated protein $C, C B S$ 34.47 and CBS 65.25, respectively, were purchased from Diagnostica Stago. Staphylocoagulase was also from Diagnostica Stago. Human $\alpha 2$-macroglobulin $(\alpha 2 \mathrm{M})$ was from Boehringer Mannheim, Mannheim, FRG. Proteins were stored frozen in concentrated solutions and diluted before use in $50 \mathrm{mM} \mathrm{NaCl}, 100 \mathrm{mM}$ Tris- $\mathrm{HCl}$ (pH 7.5) buffer containing $2 \mathrm{~g} /$ liter human albumin (HA; Sigma Chemical Co., St. Louis, MO) and $2.5 \mathrm{mM} \mathrm{CaCl} 2$.

Preliminary experiments indicated that the antibody not only inhibited the clotting activity of thrombin but also its amidolytic activity towards a synthetic substrate. We therefore investigated the inhibition of $\alpha$ thrombin and of related enzymes or enzyme complexes which display a similar amidolytic activity, i.e., gamma-thrombin, thrombomodulin-thrombin, staphylocoagulase-thrombin (staphylothrombin), and $\alpha 2 \mathrm{M}$-thrombin complexes. Thrombomodulin-thrombin and staphylothrombin were formed by incubating for $5 \mathrm{~min}$ at $37^{\circ} \mathrm{C}, \alpha-$ thrombin with twice-saturating amounts of thrombomodulin or staphylocoagulase as determined by titration experiments $(9,13)$. To prepare $\alpha 2 \mathrm{M}$-thrombin complexes, twice saturating amounts of $\alpha 2 \mathrm{M}$ (mol:mol) were reacted with $\alpha$-thrombin overnight at $4^{\circ} \mathrm{C}$. Clotting activity of staphylothrombin was $\sim 50 \%$ of that of thrombin, whereas $\alpha 2 \mathrm{M}$-thrombin had no clotting activity. The kinetic parameters $\left(K_{\mathrm{m}}\right.$, $K_{\text {cat }}$ ) of each enzymic reaction were estimated before inhibition experiments.

The inhibition of $\alpha$-thrombin or related enzyme was measured at a fixed low concentration of enzyme in the presence of varying concentrations of Fab fragments. All assays were carried out in propylene tubes at $37^{\circ} \mathrm{C}$. Enzyme $(0.5 \mathrm{nM})$ was incubated with Fab fragments $(0-100 \mathrm{nM})$ for $5 \mathrm{~min}$. CBS 34.47 was then added at various concentrations between 25 and $500 \mu \mathrm{M}$ and the mixture further incubated for 10 $\mathrm{min}$ (the rate of paranitroaniline release was linear over $10 \mathrm{~min}$ at any substrate concentration). Substrate hydrolysis was stopped by addition 
of diluted acetic acid and the absorbance at $405 \mathrm{~nm}$ was measured in a spectrophotometer (LKB Instruments, Inc., Gaithersburg, MD). The values of a blank containing the same reagents and processed in an identical way but with prior addition of acetic acid were subtracted from each experimental value. Data were analyzed as illustrated in Fig. 1 and kinetic constants determined according to Dixon (14).

Inhibition of thrombin-catalyzed protein $\mathrm{C}$ activation was investigated in two different ways. First, thrombomodulin-thrombin complexes $(1 \mathrm{nM})$ were incubated as described above with Fab fragments (0-25 $\mathrm{nM}$ ) for $5 \mathrm{~min}$ at $37^{\circ} \mathrm{C}$ before addition of protein $\mathrm{C}(0.36,0.48$, and $0.72 \mu \mathrm{M})$. After $15 \mathrm{~min}$, thrombin was inhibited by hirudin $(0.2$ $\mathrm{U} / \mathrm{ml}$ ) and $0.2 \mathrm{mM} \mathrm{CBS} 65.25$ was added. The reaction was terminated 2 min later with diluted acetic acid. Blank values were determined as above. In preliminary experiments, it was established that $(a)$ the $K_{\mathrm{m}}$ of protein $\mathrm{C}$ for the enzyme was $1.6 \mu \mathrm{M} ;(b)$ only a small proportion of protein $C(<20 \%)$ was activated; $(c)$ amidolytic reaction proceeded linearly over at least 2 min at the highest concentration of protein $C$; and $(d)$ Fab fragments did not modify the amidolytic activity of protein $\mathrm{C}$ once it had been activated by the thrombomodulin-thrombin complex.

Inhibition of thrombin-catalyzed protein $\mathrm{C}$ activation was also measured at the surface of endothelial cells. The cells were obtained from human saphenous vein (15). The activation of protein $\mathrm{C}$ and the appropriate controls were allowed to take place in $200 \mu \mathrm{l} /$ well of M199/ RPMI $1640(1: 1)$ for $2 \mathrm{~h}$ at $37^{\circ} \mathrm{C}$. The final concentrations were $2.4 \mathrm{nM}$ for thrombin, 50 and $200 \mathrm{nM}$ for protein $\mathrm{C}$, and $0-1 \mu \mathrm{M}$ for Fab fragments. The reaction was stopped with hirudin, and activated pro-
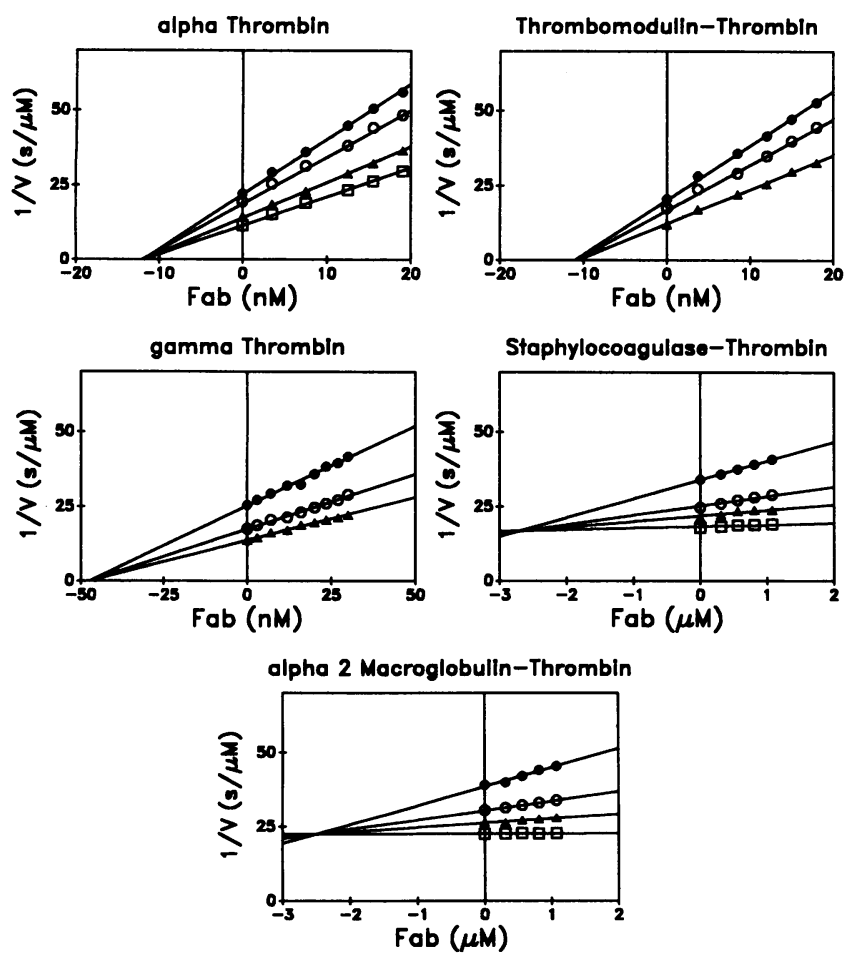

Figure 1. Inhibition of thrombin and related enzymes by Fab fragments of HA-IgG. Enzyme concentration was $0.5 \mathrm{nM}$, whereas Fab concentrations varied as indicated in abcissa. Reactions were started by addition of CBS 34.47: (•) $25 \mu \mathrm{M}$; (O) $50 \mu \mathrm{M}$; ( 1 ) $100 \mu \mathrm{M}$; (口) 500 $\mu \mathrm{M}$, and paranitroaniline formation was measured after $10 \mathrm{~min}$ of incubation at $37^{\circ} \mathrm{C}$. The $1 / \mathrm{V}$ vs. [Fab] plots gave common intercepts on the abscissa in the cases of $\alpha$-thrombin, thrombomodulin-thrombin, and gamma-thrombin at extrapolated values for $K_{\mathrm{i}}$ of 11.4, 10.6, and $47 \mathrm{nM}$, respectively. For staphylothrombin and $\alpha 2 \mathrm{M}$ thrombin, the intercepts were above the abscissa at extrapolated values for $K_{\mathrm{i}}$ of 2.7 and $2.5 \mu \mathrm{M}$, respectively, in this typical experiment. tein $\mathrm{C}$ was measured using the chromogenic substrate $\mathrm{S} 23.66$ from Kabi (Diagnostica, Mölndal, Sweden).

Thrombin affinity for benzamidine, heparin, and fibrin. Small plastic columns were packed $(0.9 \times 1 \mathrm{~cm})$ with benzamidine-Sepharose, heparin-Sepharose CL6B (both from Pharmacia Fine Chemicals AB) or fibrin-Sepharose, prepared as described by Berliner et al. (16). After equilibration, the matrices were loaded with a mixture of $0.1 \mu \mathrm{g}{ }^{125} \mathrm{I}-\alpha$ thrombin, iodinated as described in reference 17 and $10 \mu \mathrm{g}$ cold $\alpha$ thrombin, and washed with eight column volumes of equilibrating buffer. Bound thrombin was then eluted with a gradient of benzamidine (for benzamidine-Sepharose column) and a gradient of $\mathrm{NaCl}$ (for heparin- and fibrin-Sepharose columns). The experiments were repeated after preincubation of thrombin with the Fab fragments of the patient's HA-IgG and addition of Fab fragments to the washing and eluting buffers. Concentrations of Fab used were $10^{-7} \mathrm{M}$.

Proflavin binding spectral measurements. The spectral data were collected at $20^{\circ} \mathrm{C}$ with a model DU70 spectrophotometer (Beckman Instruments, Inc., Fullerton, CA). Proflavin was from Aldrich Chemical Co., Milwaukee, WI. Proflavin and thrombin stock solutions were made up fresh in $20 \mathrm{mM}$ Tris, $\mathrm{pH} 7.5,0.3 \mathrm{M} \mathrm{NaCl}$, and kept at $+4^{\circ} \mathrm{C}$ until use. Difference spectra for thrombin-proflavin complex were measured essentially as described by Berliner and Shen (18). Various concentrations of control or patient's Fab $(0-1.6 \mu \mathrm{M})$ were incubated with $\alpha$-thrombin before the addition of proflavin.

Immunoblotting. Native $\alpha$-thrombin and modified forms of thrombin $(15 \mu \mathrm{g})$ were subjected to electrophoresis on $10 \%$ polyacrylamide$0.1 \%$ SDS gels, before electroblotting to nitrocellulose paper (Bio-Rad Laboratories, Richmond, CA). Modified forms of thrombin included $\beta$ - and gamma-thrombins and thrombins irreversibly blocked at the catalytic site with diisopropylfluorophosphate $\left(\mathrm{iPr}_{2} \mathrm{P}-\mathrm{F}\right), N$ - $\alpha$-tosyl-Llysine chloromethyl ketone (TLCK) or D-phenylalanyl-L-prolyl-L-arginine chloromethyl ketone (PPACK). The residual amidolytic activity of blocked thrombins was $<0.1 \%$ of native $\alpha$-thrombin. The nitrocellulose paper was incubated for $2 \mathrm{~h}$ with the Fab fragments of the patient HA-IgG (44 nM final concentration) and the blots were revealed with ${ }^{125} \mathrm{I}$-labeled sheep $\mathrm{F}\left(\mathrm{ab}^{\prime}\right)_{2}$ fragments against human IgG (Amersham International, Amersham, UK).

\section{Results}

About $140 \mathrm{mg}$ of immunopurified IgG were recovered from $100 \mathrm{ml}$ of patient's plasma which contained $14 \mathrm{mg} / \mathrm{ml}$ of IgG. Thus, $\sim 10 \%$ of total IgG was able to bind thrombin with high affinity. This value corresponds to $1.4 \mathrm{~g} /$ liter or $9.4 \mu \mathrm{M}\left(M_{\mathrm{r}}\right.$, $150,000)$ HA-IgG in the patient's plasma. In a control experiment using a pool of normal plasma processed in a similar way, no measurable IgG was eluted from the thrombin-Sepharose column. The recovery of thrombin inhibitory activity in HAIgG was $54 \%$ of the activity initially present in the patient's plasma. As the recovery was complete after protein A affinity chromatography, it is likely that the loss of activity was due to partial denaturation during the elution with $3 \mathrm{M}$ ammonium thiocyanate, and/or to incomplete recovery during the concentration step.

The proportions of each IgG subclass in HA-IgG were 45, 42 , and $13 \%$ for $\operatorname{IgG} 1,2$, and 4 respectively. IgG 3 was lost during the protein A-Sepharose chromatography. The initial proportions of IgG subclasses in the patient's plasma were 60 , $35,2.5$, and $2.5 \%$ for IgG $1,2,3$, and 4 , respectively. The patient was heterozygous for $\mathrm{Gm}$ markers of $\mathrm{IgG1}$ : $\mathrm{Gm}(1,17)$ / (3). These markers were found in balanced proportions in HAIgG. Further arguments for the polyclonal nature of HA-IgG were the presence of both kappa and lambda light chains in the Fab fragments, and an even distribution of these fragments upon electrofocalization (data not shown). 
The kinetic parameters of CBS 34.47 hydrolysis by $\alpha$ thrombin and related enzymes such as gamma-thrombin or thrombin bound to thrombomodulin, staphylocoagulase, or $\alpha_{2} \mathrm{M}$ were similar (Table II). The Fab fragments of the patient's HA-IgG inhibited both $\alpha$-thrombin and the other forms of thrombin (Fig. 1 and Table II). The mechanism of inhibition was noncompetitive, except for staphylothrombin and $\alpha_{2} \mathrm{M}$ thrombin. The inhibition constants $\left(K_{\mathrm{i}}\right)$ for gamma-thrombin and thrombomodulin-thrombin were similar to the $K_{\mathrm{i}}$ for $\alpha$ thrombin. In contrast, the $K_{\mathrm{i}}$ for staphylothrombin and $\alpha_{2} \mathrm{M}$ thrombin were two orders of magnitude higher compared with free $\alpha$-thrombin.

Protein $\mathrm{C}$ activation by thrombin-thrombomodulin in solution was inhibited by Fab fragments with a constant of 8.2 $\mathrm{nM}$, very close to the value of $11 \mathrm{nM}$ previously found with the tripeptide CBS 34.47. Half-maximum inhibition of protein C activation on the endothelial cells surface was obtained with Fab concentrations of $45 \mathrm{nM}$ for $200 \mathrm{nM}$ protein $C$ and $53 \mathrm{nM}$ for $50 \mathrm{nM}$ protein $\mathrm{C}$ (Fig. 2). These values were five- to sixfold the $K_{\mathrm{i}}$ determined with solubilized thrombomodulin.

We examined the effect of the antibody on thrombin binding to ligands such as benzamidine, heparin, or fibrin, by comparing the elution profiles of thrombin from benzamidine-, heparin-, or fibrin-Sepharose in the absence or presence of Fab fragments from the patient HA-IgG. The Fab fragments did not prevent the binding of thrombin to insolubilized benzamidine, heparin, or fibrin and did not modify the elution profiles (not shown). To save material, the concentration of Fab used was slightly lower than thrombin concentration (ratio 1:3). However, because of the sensitivity of the method, which is able to resolve trace amounts of thrombin derivatives with lower affinity as compared with $\alpha$-thrombin (12), a decrease in affinity could not have been missed.

Proflavin binds to thrombin with an optically detectable absorption at $468 \mathrm{~nm}$, which may be measured by difference spectroscopy. The competitive binding of another ligand results spectrally in a decrease in the thrombin proflavin complex (18). Fig. 3 shows difference spectra for alpha-thrombin-proflavin complex in the presence of control or patient's Fab. The peak at $468 \mathrm{~nm}$ represents the complex, whereas the trough

Table II. Hydrolysis of the Chromogenic Substrate CBS 34-47 by Thrombin and Related Enzymes: Kinetic Parameters of the Reaction and Inhibition by Fab Fragments of Immunopurified IgG

\begin{tabular}{cccccc}
\hline Enzyme & $K_{\mathrm{m}}$ & $K_{\text {cat }}$ & $K_{\mathrm{i}}$ & $\begin{array}{c}\text { Type of } \\
\text { inhibition }\end{array}$ \\
\hline$\mu M$ & $s^{-1}$ & $M$ &
\end{tabular}

$\begin{array}{lrrrl}\text { Alpha-thrombin } & 20 & 125 & 0.9 \times 10^{-8} & \text { NC } \\ \text { Gamma-thrombin } & 25 & 150 & 5.3 \times 10^{-8} & \text { NC } \\ \text { Thrombomodulin-thrombin } & 20 & 135 & 1.1 \times 10^{-8} & \text { NC } \\ \text { Staphylocoagulase-thrombin } & 21 & 83 & 3.0 \times 10^{-6} & \mathrm{C} \\ \text { Alpha-2-macroglobulin-thrombin } & 18 & 68 & 2.5 \times 10^{-6} & \mathrm{C}\end{array}$

NC, noncompetitive; $C$, competitive.

Conditions are given in Experimental Procedures. The formula of CBS 34-47 is H-D-cyclohexylglycyl-L-alpha-aminobutyryl-L-arginineparanitroanilide. Enzymatic activity was calculated by using an absorption coefficient of $10,400 \mathrm{~cm}^{-1} . \mathrm{M}^{-1}$ for paranitroaniline at 405 nm.

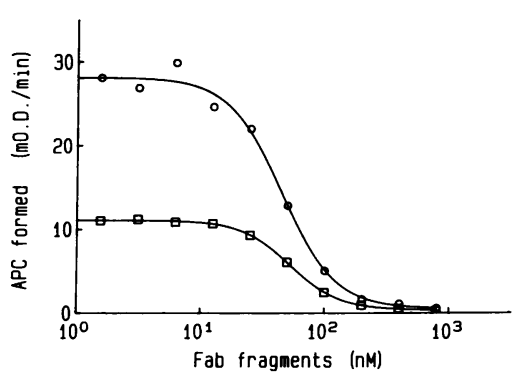

Figure 2. Inhibition of protein $\mathrm{C}$ activation by thrombin on the surface of cultured endothelial cells. The method is described in Experimental Procedures. In the absence of Fab, maximal values of activated protein C (APC) were 28 $\mathrm{mOD} / \mathrm{min}$ with $200 \mathrm{nM}$ protein $\mathrm{C}(\mathrm{O})$ and 11

$\mathrm{mOD} / \mathrm{min}$ with $50 \mathrm{nM}$ protein $\mathrm{C}(\square)$. Fab concentration giving halfmaximal inhibition were determined from a fit of the data using the equation for sigmoid curves.

near $430 \mathrm{~nm}$ accounts for free proflavin. Control Fab had no effect upon thrombin-proflavin interaction, whereas addition of the patient's Fab resulted in a partial displacement of proflavin from the thrombin-proflavin complex. Displacement of proflavin was dependent upon the patient's Fab concentration, reaching a plateau for Fab concentrations above $2 \mu \mathrm{M}$.

The Fab fragments of the patient's HA-IgG were examined for epitope specificity by immunoblotting (Fig. 4). The antibody reacted with $\alpha$-thrombin, but only in nonreducing conditions. It did not react with prothrombin nor with $\beta$ - or gammathrombin. Inactivation of $\alpha$-thrombin with various catalytic center-directed irreversible inhibitors modified the interaction with the inhibitor (Fig. 4, lanes $f-h$ ). Binding to iPr2P-thrombin was decreased as compared with active $\alpha$-thrombin. Radioactivity of the corresponding bands was counted: binding of the Fab fragments to iPr2P-thrombin was $20 \%$ of the binding to active $\alpha$-thrombin. As active thrombin was $<0.1 \%$ in our preparation of $\mathrm{iPr} 2 \mathrm{P}$-thrombin, the antibody interaction with iPr2P-thrombin could not be ascribed to binding this very small amount of active thrombin. It was more likely that the linkage of the iPr2P-group to Ser 205 in the thrombin B chain actually decreased the affinity of the antibody for the enzyme. The antibody did not react with TLCK- or PPACK-thrombin.

\section{Discussion}

This report describes a patient with a fatal bleeding disorder associated with an acquired potent thrombin inhibitor directed

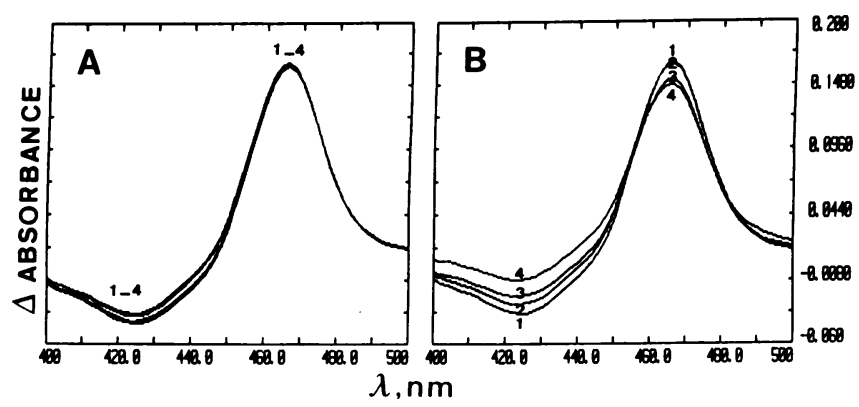

Figure 3. Difference absorption spectra of proflavin solutions. Reference curvette contains $10 \mu \mathrm{M}$ proflavin in $20 \mathrm{mM}$ Tris, pH 7.5, 0.3 M $\mathrm{NaCl}$. Samples contain $10 \mu \mathrm{M}$ proflavin, $10 \mu \mathrm{M}$ human alphathrombin, and various concentrations of control Fab $(A)$ or patient's antithrombin $\mathrm{Fab}(B)$ in the same buffer. Final concentrations of $\mathrm{Fab}$ were (1) 0 , (2) $0.4 \mu \mathrm{M}$, (3) $0.9 \mu \mathrm{M}$, (4) $1.6 \mu \mathrm{M}$ 

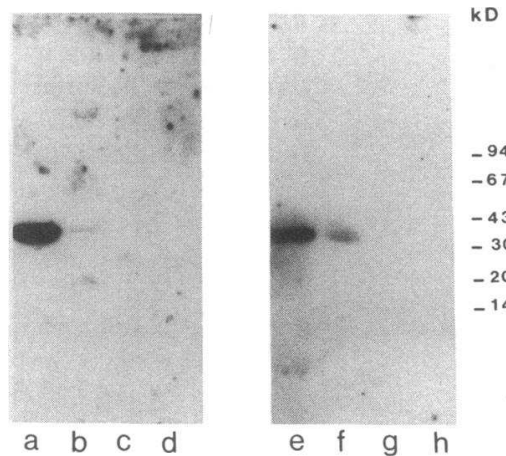

Figure 4. Immunoblot analysis of the reactivity of the patient's antibody with prothrombin and various forms of thrombin. $15 \mu \mathrm{g}$ of $\alpha$ thrombin ( $a$ and $e$ ), $\beta$ thrombin $(b)$, gammathrombin $(c)$, prothrombin $(d)$, iPr2Pthrombin $(f)$, TLCKthrombin $(g)$, PPACKthrombin $(h)$ were electrophoresed in

nonreducing conditions on SDS-PAGE slab gels, and the proteins were transferred to a nitrocellulose membrane. Strips of the membrane were processed for immunoblotting using Fab from the patient's HA-IgG (44 nM final concentrations) as the primary antibody followed by ${ }^{125}$ I sheep $F\left(a^{\prime}\right)_{2}$ fragments against human IgG.

against the catalytic center of the enzyme. The inhibitory activity in plasma was approximately equivalent to $3 \mathrm{IU} / \mathrm{ml}$ of standard heparin when we saw the patient for the first time but APTT, PT, and TT had been out of limits for at least two years before.

The thrombin inhibitor was isolated from the patient's plasma by affinity chromatography using insolubilized thrombin and consisted of a population of polyclonal IgG. Because the proportion of thrombin-neutralizing antibodies in this population is unknown, the apparent inhibition constants determined in the kinetic experiments should be regarded as maximal values for the true constants of neutralizing antibodies.

Thrombin is a serine-protease with unique interactions with various substrates or ligands, in plasma or cell membranes. The thrombin active site confers its unique properties to the enzyme (19). The three residues His 43, Asp 99, Ser 205 constitute the catalytic site per se, with Asp 199 as the counter ion at the bottom of the arginine side chain pocket. Adjacent to the catalytic site is a prominent apolar binding site which appears to be of major importance in determining thrombin specificity with peptide and protein substrates $(18,20,21)$. In addition, proper accommodation of macromolecular substrates or ligands requires recognition site(s) which are remote from the catalytic site $(16,19)$. The neutralizing activity of the inhibitor was demonstrated whatever the thrombin substrate used: fibrinogen, protein C, or the small peptide CBS 34.47. Because the structures of the active site involved in the hydrolysis of small peptides are limited to the catalytic triad, the arginine side chain pocket and the adjacent apolar binding site, we hypothesized that the antibody was directed against epitopes closely associated with the catalytic site, rather than located in the protein recognition site(s).

To confirm this hypothesis, we measured the affinity of the antibody for various forms of thrombin, which are all characterized by minimal modifications in the catalytic site and adjacent structures, contrasting with large alterations in the recognition of macromolecular substrates or ligands. These forms included gamma-thrombin which derives from $\alpha$-thrombin by limited proteolysis, and $\alpha$-thrombin bound to human thrombomodulin, staphylocoagulase or $\alpha_{2} M$. The inhibitor retained the ability to neutralize the amidolytic activity of all these thrombin forms. Thrombomodulin binds thrombin to a site that probably overlaps a site required for binding or steric accommodation of fibrin(ogen) $(12,22,23)$. The conformational change in the active site of thrombin that results from this binding (24) did not mask the epitopes because the inhibition constant of the antibody was unchanged upon binding of $\alpha$ thrombin to soluble thrombomodulin. The affinity of the antibody for $\alpha$-thrombin bound to cellular thrombomodulin was slightly weaker when compared with $\alpha$-thrombin bound to solubilized thrombomodulin. This could be explained by steric hindrance because the active center of thrombin is separated from the membrane surface by a distance of only $66 \AA$ (25).

As compared to $\alpha$-thrombin, the affinity of the antibody for gamma-thrombin was also slightly weaker (sixfold). Although the cleavages responsible for $\alpha$ - to gamma-thrombin conversion affect regions of the thrombin $B$ chain that are remote from the catalytic site (26-28), they induce a slight constraint in the environment of the catalytic site $(12,29)$ which may have been detected by the antibody. The proteolytic cleavages that convert $\alpha$ - to gamma-thrombin affect the anion binding exosite $(26,27,30)$ involved in fibrin $(12,22,30)$ and heparin (19) binding. The lack of effect of our antibody on the affinity of $\alpha$-thrombin for either fibrin or heparin is an additional evidence that the epitopes recognized by the antibody are not located in the anion binding exosite.

The inhibition of staphylothrombin and $\alpha_{2} \mathrm{M}$-thrombin by the antibody proceeded with a lower affinity (two orders of magnitude) compared with free $\alpha$-thrombin, and was competitive. Staphylocoagulase interacts with $\alpha$-thrombin through the $\mathrm{COOH}$-terminal region of the thrombin $\mathrm{B}$ chain and alters the microenvironment of the catalytic site (13). These changes could account for the reduced affinity of the antibody for staphylothrombin. Alternatively, staphylocoagulase bound to thrombin could sterically hinder the access of the antibody to the epitopes. The catalytic site of thrombin remains intact in the irreversible $\alpha_{2}$ M-thrombin complex as judged by the ability to hydrolyze small substrates, but the enzyme is sterically hindered by entrapment within $\alpha_{2} \mathrm{M}$ and hydrolysis of large proteins is inhibited $(31,32)$. There is general agreement that the antigenicity of most proteinases bound to $\alpha_{2} M$ is greatly reduced (33) although the extent of reduction varies with the proteinase involved. The internal dimensions of the $\alpha_{2} \mathbf{M}$ cylinder (34) would allow total entrapment of thrombin. However, our antibody gained access to thrombin complexed with $\alpha_{2} \mathbf{M}$, suggesting that the epitopes, and consequently the catalytic site and adjacent structures, are not buried deep in the center of the $\alpha_{2} \mathbf{M}$ cylinder.

Immunoblot experiments provide further evidence that the antibody is directed against a conformational structure closely associated with the catalytic site. The antibody reacted with active $\alpha$-thrombin but did not react with TLCK- or PPACKthrombin. In contrast, it reacted with iPr2P-thrombin although with a lower affinity as compared with active $\alpha$-thrombin. Peptidyl chloromethyl ketones attached to the catalytic histidine (His 43) accommodate tightly with neighboring sites (arginine side-chain pocket and apolar binding site). iPr2PF binds irreversibly to the catalytic serine (Ser 205) without binding neighboring sites, although the access to these sites may be impaired by the very sterically hindering iPr2P-group. The result of the immunoblots obtained with active and inactivated $\alpha$-thrombins indicates that the epitopes do not include Ser 205, but are located close enough to be partially masked by the iPr2P-group attached to Ser 205. Benzamidine is a small cationic com- 
pound which binds to the arginine side chain pocket without significant extension beyond this pocket (35). The antibody did not alter the affinity of thrombin for benzamidine-Sepharose, giving indirect evidence that the apolar binding site rather than the arginine side chain pocket contains the antigenic determinants.

The acridine dye, proflavin, has previously been shown to bind to an apolar binding site adjacent to the catalytic site, distinct from hydrophobic regions of the arginine side chain pocket (18) and extending into the fibrinopeptide groove (21). Displacement of proflavin from the thrombin-proflavin complex by the patient's Fab confirmed that the structure recognized by the antibody includes, at least in part, the apolar binding site (Fig. 5).

The epitopes were not detected by immunoblotting in $\beta$ - or gamma-thrombin, although kinetic experiments showed that the affinity of the antibody was similar for $\alpha$ - and gammathrombin. Although the catalytic site is functional in $\beta$ - and gamma-thrombins, the structural determinants reside on noncovalently associated fragments. The lack of reactivity of the antibody with $\beta$ - and gamma-thrombins indicates that the epitopes are destroyed by dissociation of the fragments in SDS gels. Further evidence that the epitopes are conformation-dependent is given by the absence of reactivity of the antibody with prothrombin and the suppression of reactivity with $\alpha$ thrombin upon disulfide bonds reduction.

Considering the plasma concentrations of thrombin-binding IgG $\left(10^{-5} \mathrm{M}\right)$, the concentration of prothrombin, the antigen precursor $\left(10^{-6} \mathrm{M}\right)$, and the low inhibition constant of the interaction $\left(10^{-8} \mathrm{M}\right)$, free thrombin could not escape inhibition even in the case of complete and rapid prothrombin activation at vascular wounds. Thrombin bound to macromolecules (e.g., thrombomodulin, fibrin, etc.) could be protected from intact IgG by steric hindrance if in these particular environments the access of the antibody to the catalytic center of the enzyme is impaired. In this respect, it is important to recall that the patient had the antibody for at least two years without evidence of major bleeding and that the terminal event may have been precipitated by other hemostatic defects such as thrombocytopenia and hypoprothrombinemia.

Although the criteria required for the diagnosis of systemic lupus erythematosus were not fulfilled (7), the evidence of autoimmune disease was strong. However, the production of an autoantibody with such precise specificity is intriguing. Exposure of the intrinsic antigen to B lymphocytes may have oc-

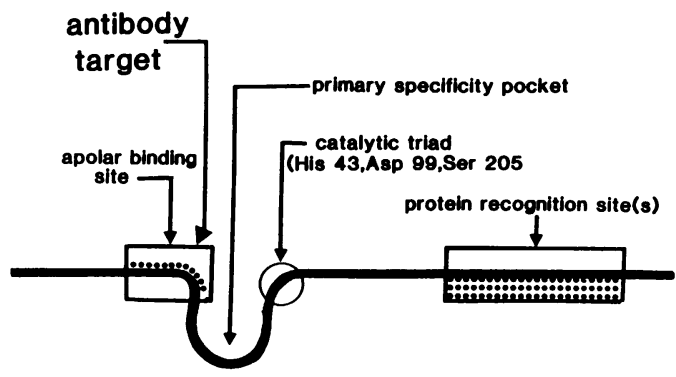

Figure 5. Schematic map of thrombin active site region (adapted from reference 36). Besides the catalytic triad, recognition sites include the primary specificity pocket and a secondary binding area subdivided into one or several protein recognition site(s) and an apolar binding site, which is the proposed target of the patient's antibody. curred because low levels of thrombin production have been indirectly demonstrated in normal subjects (37). Alternatively, exposure to cross-reactive enzymes in the external environment cannot be excluded but nothing in patient's medical history was indicative in this regard. The antibody found in our patient joins the class of antienzyme autoantibodies which have been reported in various human diseases (38-44). In some instances (38-41), functional studies have suggested that the autoantibodies may be directed against a site essential for catalysis. The present observation raises the important consideration that autoantibodies against the catalytic site of serine proteases may be found during autoimmune processes.

\section{Acknowledgments}

We are indebted to Pr. J. Pris and Dr. G. Fournié for helpful discussion, and to Dr. M. P. Cabrol for referring the patient.

This work was supported by a grant from the Université Paul Sabatier, Toulouse, and from the Institut National de la Santé et de la Recherche Médicale (CRE 87 5007).

\section{References}

1. Fleck, R. A., S. I. Rapaport, and L. V. M. Rao. 1988. Anti-prothrombin antibodies and the lupus anticoagulant. Blood. 72:512-519.

2. Lawson, J. H., B. J. Pennell, J. D. Olson, and K. G. Mann. 1990. Isolation and characterization of an acquired antithrombin antibody. Blood. 76:22492257.

3. Struzik, T., Z. Hanicki, J. Hawiger, and B. Biernacka. 1964. Cryo-coagulopathy with presence of immunoantithrombin in the course of lupus erythematosus disseminatus. Acta Medica Polona. V:61-80.

4. Barthels, M., and N. Heimburger. 1985. Acquired thrombin inhibitor in a patient with liver cirrhosis. Haemostasis. 15:395-405.

5. Gabriel, D. A., M. E. Carr, L. Cook, and H. R. Roberts. 1987. Spontaneous antithrombin in a patient with benign paraprotein. Am. J. Med. 25:85-93.

6. Scully, M. F., V. Ellis, V. V. Kakkar, G. F. Savidge, Y. F. Williams, and H Sterndale. 1982. An acquired coagulation inhibitor to factor II. Br. J. Haematol. 50:655-664.

7. Tan, E. M., A. S. Cohen, J. F. Fries, A. T. Masi, D. J. McShane, N. F. Rothfield, J. G. Schaller, N. Talal, and R. J. Winchester. 1982. The 1982 revised criteria for the classification of systemic lupus erythematosus. Arth. Rheum. 25:1271-1277.

8. Field, L. L., and J. M. Dugoujon. 1989. Immunoglobulin allotyping (Gm, Km) of GAW 5 families. Gen. Epidemiol. 6:31-33.

9. Freyssinet, J. M., J. Gauchy, and J. P. Cazenave. 1986. The effect of phospholipids on the activation of protein $\mathrm{C}$ by the human thrombin-thrombomodulin complex. Biochem. J. 238:151-157.

10. Bezeaud, A., M. H. Denninger, and M. C. Guillin. 1985. Interaction of human alpha-thrombin and gamma-thrombin with antithrombin III, protein C and thrombomodulin. Eur. J. Biochem. 153:491-496.

11. Freyssinet, J. M., A. Beretz, C. Klein-Soyer, J. Gauchy, S. Schuhler, and J. P. Cazenave. 1988. Interference of blood-coagulation vitamin K-dependent proteins in the activation of human protein $\mathrm{C}$. Involvement of the 4-carboxyglutamic acid domain in two distinct interactions with the thrombin-thrombomodulin complex and with phospholipids. Biochem. J. 256:501-507.

12. Bezeaud, A., and M. C. Guillin. 1988. Enzymic and noenzymic properties of human $\beta$-thrombin. J. Biol. Chem. 263:3576-3581.

13. Kawabata, S. I., T. Morita, S. Iwanaga, and H. Igarashi. 1985. Difference in enzymatic properties between alpha-thrombin-staphylocoagulase complex and free alpha-thrombin. J. Biochem. 97:1073-1078.

14. Dixon, M., and E. C. Webb. 1964. Enzymes. 2nd ed. Longmans, Green, London.

15. Beretz, A., J. M. Freyssinet, J. Gauchy, D. A. Schmitt, C. Klein-Soyer, C. J. S. Edgell, and J. P. Cazenave. 1989. Stability of the thrombin-thrombomodulin complex on the surface of endothelial cells from human saphenous vein or from the cell line EA.hy 926. Biochem. J. 259:35-40.

16. Berliner, L. J., Y. Sugawara, and J. W. Fenton. 1985. Human Ä-thrombin binding to nonpolymerized fibrin-Sepharose: evidence for an anionic binding region. Biochemistry. 24:7005-7009.

17. Jandrot-Perrus, M., D. Dedry, M. C. Guillin, and A. T. Nurden. 1988. Cross-linking of $\alpha$ and gamma-thrombin to distinct binding sites on human platelets. Eur. J. Biochem. 174:359-367.

18. Berliner, L. J., and Y. Y. L. Shen. 1977. Physical evidence for an apolar 
binding site near the catalytic center of human A-thrombin. Biochemistry. $16: 4622-4626$

19. Fenton, J. W., and D. H. Bing. 1986. Thrombin active-site regions. Semin. Thromb. Hemost. 12:200-208.

20. Bing, D. H., R. Laura, D. J. Robinson, B. C. Furie, and R. J. Feldman. 1981. A computer-generated three-dimensional model of the $B$ chain of bovine Ä-thrombin. Ann. NY Acad. Sci. 370:496-510.

21. Sonder, S. A., and J. W. Fenton. 1984. Proflavin binding within the fibrinopeptide groove adjacent to the catalytic site of human Á-thrombin. Biochemistry. 23:1818-1823.

22. Noe, G., J. Hofsteenge, G. Rovelli, and S. R. Stone. 1988. The use of sequence-specific antibodies to identify a secondary binding site in thrombin. $J$. Biol. Chem. 263:11729-11735.

23. Jakubowski, H. V., M. D. Kline, and W. G. Owen. 1986. The effect of bovine thrombomodulin on the specificity of bovine thrombin. J. Biol. Chem 261:3876-3882.

24. Musci, G., L. J. Berliner, and C. T. Esmon. 1988. Evidence for multiple conformational changes in the active center of thrombin induced by complex formation with thrombomodulin: an analysis employing nitroxide spin-labels. Biochemistry. 27:73-76.

25. Esmon, C. T. 1989. The roles of protein C and thrombomodulin in the regulation of blood coagulation. J. Biol. Chem. 264:4743-4746.

26. Chang, J. Y. 1986. The structures and proteolytic specificities of autolyzed human thrombin. Biochem. J. 240:797-802.

27. Boissel, J. P., B. Le Bonniec, M. J. Rabiet, D. Labie, and J. Elion. 1984 Covalent structures of $\beta$ and gamma autolytic derivatives of human $\alpha$-thrombin. J. Biol. Chem. 259:5691-5697.

28. Braun, P. J., J. Hofsteenge, J. Y. Chang, and S. R. Stone. 1988. Preparation and characterization of proteolyzed forms of human $\alpha$-thrombin. Thromb. Res. 50:273-283.

29. Berliner, L. J., R. S. Bauer, T. L. Chang, J. W. Fenton, and Y. Y. L. Shen. 1981. Active site topography of human coagulant $(\alpha)$ and noncoagulant (gamma) thrombins. Biochemistry. 20:1831-1837.

30. Fenton, J. W., T. A. Olson, M. P. Zabinski, and G. D. Wilner. 1988. Anion-binding exosite of human alpha-thrombin and fibrin(ogen) recognition. Biochemistry. 27:7106-7112.

31. Downing, M. R., J. W. Bloom, and K. G. Mann. 1978. Comparison of the inhibition of thrombin by three plasma protease inhibitors. Biochemistry. 17:2649-2653.

32. Pochon, F., and M. Steinbuch. 1984. Interaction of alpha-2-macroglobu- lin-bound thrombin with hirudin. FEBS (Fed. Eur. Biochem. Soc.) Lett. 177:109-111.

33. Roberts, R. C. 1986. $\alpha$-2-Macroglobulin. J. Med. 16:129-224.

34. Feldman, S. R., S. L. Gonias, and S. V. Pizzo. 1985. Model of $\alpha$-2-macroglobulin structure and function. Proc. Natl. Acad. Sci. USA. 82:5700-5704.

35. Geratz, J. D., and R. R. Tidwell. 1977. The development of competitive reversible thrombin inhibitors. In Chemistry and Biology of Thrombin. R. L. Lundblad, J. W. Fenton, and K. G. Mann, editors. Ann Arbor Science Publishers, Ann Arbor, MI. 179-196.

36. Fenton, J. 1981. Thrombin specificity. Ann. NY Acad. Sci. 370:468-495.

37. Bauer, K. A., L. M. Weiss, D. Sparrow, P. S. Vokonas, and R. D. Rosenberg. 1987. Aging-associated changes in indices of thrombin generation and protein C activation in humans. J. Clin. Invest. 80:1527-1534.

38. Shero, J. H., B. Bordwell, N. F. Rothfield, and W. C. Earnshaw. 1986. High titers of autoantibodies to topoisomerase I ( $\mathrm{Scl}-70)$ in sera from scleroderma patients. Science (Wash. DC). 231:737-740.

39. Dang, C. V., E. M. Tan, and J. A. Traugh. 1988. Myositis autoantibody reactivity and catalytic function of threonyl-tRNA synthetase. FASEB (Fed. Am. Soc. Exp. Biol.) J. 28:2376-2379.

40. Yamanaka, H., E. H. Willis, and D. A. Carson. 1989. Human autoantibodies to poly(adenosine diphosphate-ribose)polymerase recognize cross-reactive epitopes associated with the catalytic site of the enzyme. J. Clin. Invest. 83:180186.

41. Yamanaka, H., E. H. Willis, C. A. Penning, C. L. Peebles, E. M. Tan, and D. A. Carson. 1987. Human autoantibodies to poly(adenosine diphosphate-ribose) polymerase. J. Clin. Invest. 80:900-904.

42. Falk, R. J., and J. C. Jennette. 1988. Anti-neutrophil cytoplasmic autoantibodies with specificity for myeloperoxidase in patients with systemic vasculitis and idiopathic necrotizing and crescentic glomerulonephritis. N. Engl. J. Med. 318:1651-1657.

43. Goldschmeding, R., C. E. van der Schoot, J. W. Cohen Tervaert, D. Y Mason, A. E. G. K. von dem Borne, and C. G. M. Kallenberg. 1988. Autoantibodies against myeloid lysosomal enzymes: a novel class of autoantibodies associated with vasculitic syndromes. Kidney Int. 34:558-559. (Abstr.)

44. Goldschmeding, R., C. E. van der Schoot, D. ten Bokkel Huinink, C. E. Hack, M. E. van den Ende, C. G. M. Kallenberg, and A. E. G. K. von dem Borne. 1989. Wegener's granulomatosis autoantibodies identify a novel diisopropylfluorophosphate-binding protein in the lysosomes of normal human neutrophils. J. Clin. Invest. 84:1577-1587. 